\title{
Sufficiently premixed compression ignition of a gasoline-like fuel using three different nozzles in a diesel engine
}

\author{
H-W Won ${ }^{1,2}$, N Peters ${ }^{1}$, N Tait $^{2}$, and G Kalghatgi ${ }^{3}$ \\ ${ }^{1}$ Institute for Combustion Technology, RWTH Aachen University, Aachen, Germany \\ ${ }^{2}$ Shell Global Solutions, Chester, UK \\ ${ }^{3}$ Saudi Aramco, Dhahran, Saudi Arabia
}

The manuscript was received on 9 May 2011 and was accepted after revision for publication on 24 August 2011.

DOI: $10.1177 / 0954407011423453$

\begin{abstract}
Fuels that are more resistant to autoignition allow more time for mixing before combustion occurs and help to reduce nitrogen oxides $\left(\mathrm{NO}_{x}\right)$ and smoke in a diesel engine. However, hydrocarbon (HC) and carbon monoxide (CO) emissions are high at low loads because combustion is more likely to take place in lean mixture packets with better mixing caused by longer ignition delays. These problems can be significantly alleviated by managing the mixture strength by changing the injection pressure and the nozzle geometries. A singlecylinder diesel engine is run on a mixture of gasoline and diesel with a research octane number of 91, at different speeds, loads, and exhaust gas recirculation levels using three different nozzles. It is much easier to obtain low $\mathrm{NO}_{x}$ and low smoke emissions with this fuel than with a European diesel fuel using the standard nozzle. Larger injector holes and lower injection pressures help to reduce the $\mathrm{HC}$ and $\mathrm{CO}$ emissions at low loads and also enable the gasolinelike fuel to run at a higher speed of $4000 \mathrm{r} / \mathrm{min}$ at a reasonably high load (indicated mean effective pressure) of 10 bar.
\end{abstract}

Keywords: future fuel, partially premixed compression ignition, autoignition quality, diesel engine, emission

\section{INTRODUCTION}

Conventional compression ignition (CI) diesel engines have a low indicated specific fuel consumption (ISFC) and thus low carbon dioxide $\left(\mathrm{CO}_{2}\right)$ emissions because of the lack of throttling losses and also the high compression ratio. However, diesel engines suffer from high nitrogen oxide $\left(\mathrm{NO}_{x}\right)$ and soot emissions. These emissions are strongly dependent on the distribution of fuel and its mixing with air. In diesel engines, combustion of the diesel fuel, which is injected into the high-temperature highpressure chamber directly, starts before the fuel has mixed properly with oxygen. Injection continues

*Corresponding author: Shell Global Solutions, P. O. Box 1, Chester CH1 3SH, UK.

email: hyun-woo.won@shell.com until the desired amount of fuel has entered the cylinder. Atomization, vaporization, air-fuel mixing, and combustion continue until essentially all the fuel has passed through each process. In addition, mixing of the air remaining in the chamber with burning and already burned gases continues throughout the combustion and expansion processes. However, the short-ignition-delay characteristic of conventional diesel fuels makes combustion take place in relatively rich mixtures and causes high levels of soot and $\mathrm{NO}_{x}$ to be formed. Soot formation can be minimized by ensuring that the equivalence ratio of the mixture packets where combustion occurs is not greater than $\varphi>\sim 2$ or $\lambda<\sim 0.5$ [1], where $\varphi$ is the equivalence ratio and $\lambda=1 / \varphi$ is the normalized air-to-fuel ratio. $\mathrm{NO}_{x}$ formation can be minimized if the combustion temperatures are kept below about $2200 \mathrm{~K}$ [1]. This can be achieved 
either by running the engine lean, with $\lambda$ much greater than 1 , or by using high levels of exhaust gas recirculation (EGR). At low loads, when the amount of fuel needed is low, for a fixed injector and injection pressure the injection duration needs to be short and the injection event is finished before combustion starts. Under these conditions, most combustion occurs in a 'premixed' mode, in mixture packets which have been mixed with oxygen to varying degrees. The fuel injected first will have had a longer time to mix and hence will have a lower $\varphi$ than the fuel that is injected at the end of the injection pulse. In conventional diesel combustion the peak heat release rate and hence the temperature will be high because the mixture packets will be fuel rich, i.e. $\varphi>1$. This high temperature will cause high levels of $\mathrm{NO}_{x}$ to be formed. Even when smoke is formed, if there is sufficient oxygen and the temperature is high enough, it will be oxidized inside the cylinder and engine-out levels will be low. When EGR is increased to control the $\mathrm{NO}_{x}$ level, the oxygen levels in the cylinder as well as the temperature decrease and, if any smoke is formed in the first place, it does not become oxidized and the engineout levels will be high. At higher loads, which require more fuel to be injected, it is impossible with diesel to complete the injection before ignition occurs owing to the short ignition delay times. Following ignition, 'diffusion' flame fronts are established after which additional fuel injected will burn in a diffusion mode. Many strategies such as using a high-pressure injection to increase the mixing rates and injection after top dead centre (ATDC) and reduction in the compression ratios to slow down the chemical reaction rates are used to promote premixed low-temperature combustion in diesel engines using diesel fuel. Even then, aftertreatment systems will most probably be needed to control the $\mathrm{NO}_{x}$ and smoke emissions in high-load conditions. This technology makes the advanced diesel engine very expensive and complicated and might reduce the fuel economy and thus the primary advantage of diesel engines. Emissions from diesel engines also depend on the combustion phasing which is controlled by the injection timing. If combustion occurs before top dead centre (BTDC), this can lead to unacceptably high pressure rise rates and noise. Heat release can be made to occur ATDC by choosing the right injection timing, and the pressure rise rates can be reduced for a given maximum heat release rate. On the other hand, the crank angle at which 50 per cent of the total heat is released, denoted CA50, should not occur later than about $11^{\circ}$ crank angle (CA) ATDC; otherwise the efficiency decreases [2]. Several operating strategies have been employed to promote premixed and lowtemperature combustion in diesel engines. In homogeneous charge compression ignition (HCCI) the fuel and air are fully premixed as in a spark ignition engine and compressed until the charge autoignites. In modern direct-injection diesel engines with common-rail injection systems, HCCI combustion can be obtained by injecting the diesel fuel very early in the cycle, giving it sufficient time to mix completely with air. However, with HCCI, there is no in-cycle control over the phasing of the heat release, which will be determined by the initial conditions of the mixture at the start of the compression stroke and the autoignition characteristics of the fuel. Hence HCCI combustion is very difficult to control. Recent work has shown that, when a fuel with a high ignition delay, in the gasoline autoignition range, is injected near top dead centre (TDC), it ignites much later than diesel fuel, and combustion occurs when fuel and air have had more chance to mix [3-9]. If the same amount of gasoline is injected early in the same condition, i.e. with fully premixed HCCI conditions, ignition might not occur at all. Thus inhomogeneity is essential for combustion to happen when fuel and air are better mixed, i.e. fuel and air are sufficiently premixed but must not be fully premixed. This mixture stratification, which enables control of the phasing of combustion through injection timing, is easily achieved simply by relatively late injection compared with HCCI. Much higher loads can be also achieved at low smoke and $\mathrm{NO}_{x}$ levels using gasoline compared with diesel, while retaining control over combustion. However, partially premixed compression ignition (PPCI) operation also leads to higher carbon monoxide (CO) and hydrocarbon (HC) emissions at low loads and higher heat release rates at high loads. These problems can be significantly alleviated by managing the mixing through injector design and injection strategies (e.g. multiple injection). Thus larger injector hole diameters and lower injection pressures might be better for gasoline fuels. The resistance to autoignition of a fuel is far more important than its volatility in this type of combustion [7-12]. The volatility of fuels for this type of combustion might be determined by manufacturing considerations rather than by engine requirements. Such fuels, with a lower octane than today's gasoline but with more relaxed volatility specifications might offer benefits in terms of better manufacturing efficiencies. Low- $\mathrm{NO}_{x}$ low-smoke high-efficiency CI combustion is likely to benefit from poor-quality diesel (low cetane number $(\mathrm{CN})$ ) and gasoline (lower research octane number $(\mathrm{RON})$ than that of current gasoline) by today's standards and lower 


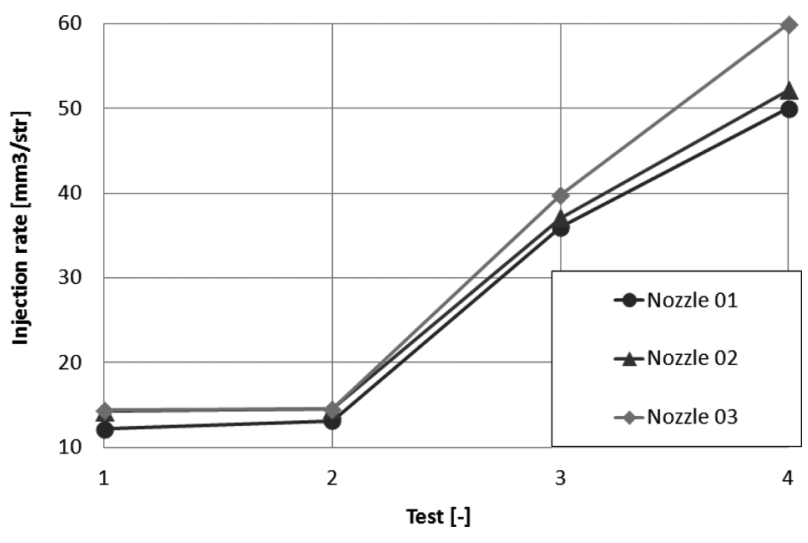

Fig. 1 Injection flowrates for three nozzles at different injection pressures and injection durations: test 1, 250 bar for $1220 \mu \mathrm{s}$; test 2, 400 bar for $800 \mu \mathrm{s}$; test 3, 600 bar for $1060 \mu \mathrm{s}$; test 4, 600 bar for $1500 \mu \mathrm{s}$

injection pressures using enlarged-orifice nozzles compared with those of current diesel engines. Hence there is much incentive and also scope to develop such engine combustion systems. More recently, groups at Lund University $[13,14]$ and Wisconsin University (see, for example, reference [15]) have demonstrated that heavy-duty diesel engines can be run on gasoline as well as ethanol with a very high efficiency and very low $\mathrm{NO}_{x}$ and smoke emissions. Weall and Collings have also demonstrated the benefits of low-reactivity fuels by studying mixtures of gasoline and diesel [16] and have also addressed the issues arising from running a diesel engine on gasoline at low loads and low speeds [17]. Sellnau et al. [18] have demonstrated that this type of combustion with gasoline could give diesellike efficiencies with low emissions. In this study a blended fuel (90 percent of 95RON gasoline and 10 per cent of $56 \mathrm{CN}$ diesel) is tested in a single-cylinder direct-injection diesel engine at different operating conditions and the results are compared with a European diesel fuel. It is important to avoid 'overmixing' the fuel with oxygen in low-load conditions. At the same time, it is also important to avoid a vapour lock in the injection system high-octane fuels which have low boiling temperatures. With such fuels, lower injection pressures result in better combustion stability and significantly lower $\mathrm{HC}$ and $\mathrm{CO}$ emissions without compromising the $\mathrm{NO}_{x}$ or smoke emissions. Three different nozzles are used for this study. Nozzle 01 with a $0.13 \mathrm{~mm}$ orifice diameter is a standard nozzle for diesel and two more nozzles with higher flow numbers (FNs) than the standard nozzle are designed for the blended fuel. The FN of nozzle 02 with the same orifice diameter $(0.13 \mathrm{~mm})$ is increased with honing, and nozzle 03 has the highest
FN with a $0.17 \mathrm{~mm}$ orifice diameter and honing. Figure 1 shows the different flowrates of each nozzle with different injection pressures and durations. Clearly the flowrate changes do not correspond to the external orifice diameters quoted earlier, which were measured using an electron microscope. Nozzle 03 was made by first laser welding the holes of a duplicate nozzle 01, next drilling the larger hole size, and then honing it. There are clearly factors (perhaps cavitation) that affect the discharge coefficient of this nozzle. Otherwise the flowrate would have increased by a factor which is the square of the external nozzle diameters quoted above.

\section{EXPERIMENTAL SET-UP}

\subsection{Engine}

The experiments were performed on a 0.5371 singlecylinder research engine with a 15.9:1 compression ratio. The specifications of the single-cylinder engine are given in Table 1. All experiments were carried out with coolant and oil temperatures of $90^{\circ} \mathrm{C}$, and the inlet air temperature was kept at $60^{\circ} \mathrm{C}$. Fuel was injected via a Bosch 7 hole injector, with an injector cone angle of $153^{\circ}$, fed by an independent fuel supply rig. The injectors are controlled using an IAV injection controller to keep a constant injection pressure, injection timing, and indicated mean effective pressure (IMEP). An external air compressor was used to simulate boosted conditions. When EGR was introduced, the exhaust back pressure was set 0.2 bar higher than the inlet manifold air pressure and the recirculated gases were cooled using an external cooling circuit to the same temperature as the inlet air, i.e. $60^{\circ} \mathrm{C}$. The in-cylinder pressure was measured with a water-cooled pressure transducer (Kistler 6041 A). The emissions and the inlet $\mathrm{CO}_{2}$ level were measured using a Horiba MEXA-9500 $\mathrm{H}$ system, and soot was measured using an AVL 415 smoke meter. After a stabilization period, the emissions were logged once per second for $60 \mathrm{~s}$, and the averages of those 60 recordings are the values that are presented in this paper. At the same time, the in-cylinder pressure was recorded for 250 cycles.

\subsection{Fuels}

Conventional diesel has a much lower RON than currently available gasoline fuel does. Correspondingly, currently available gasoline fuel has a much lower CN than currently available diesel fuel does. A blend of currently available gasoline fuel and diesel fuel yields a fuel composition having both a lower 
Table 1 The specifications of the single-cylinder engine

\begin{tabular}{ll}
\hline Engine & Single-cylinder engine \\
\hline Displacement volume (l/cylinder) & 0.537 \\
Bore $(\mathrm{mm})$ & 88 \\
Stroke $(\mathrm{mm})$ & 88.3 \\
Connecting-rod length $(\mathrm{mm})$ & 149 \\
Compression ratio & $15.9: 1$ \\
\hline
\end{tabular}

RON and a lower $\mathrm{CN}$ than the individual gasoline fuel and diesel fuel respectively, which is especially suitable for PPCI engines. The ignition quality of the blended fuel can be varied as needed to meet the requirements of the PPCI engine. A blended fuel (90 vol \% of $95 \mathrm{RON}$ gasoline and $10 \mathrm{vol} \%$ of $56 \mathrm{CN}$ diesel fuel), which is named 'GD10', is used in present study and compared with the result for diesel fuel (D1). The volatility characteristics of these fuels are shown in Fig. 2, where the volume percentage recovered at a given temperature in the ASTM volatility test is plotted against the temperature. The fuel properties are listed in Table 2. The diesel fuel is a commercial low-sulphur European diesel fuel with a $\mathrm{CN}$ of 56 with a boiling-point range between $162^{\circ} \mathrm{C}$ and $365^{\circ} \mathrm{C}$ while the boiling-point range of the gasoline fuel is between $46^{\circ} \mathrm{C}$ and $195^{\circ} \mathrm{C}$. The fuels had a sufficient amount of lubricity additive (300 ppm of Paradyne R655 from Infineum) to ensure that the lubricity scar size was well within the European specification. It can also be seen from Table 2 that all the fuels have similar gravimetric heats of combustion. The fuel consumption was calculated using the measured exhaust emissions and air consumption rate because there were problems of stability with the fuel flow meter at the low flowrates encountered for the volatile fuels; this is less desirable than direct measurements of the fuel consumption.

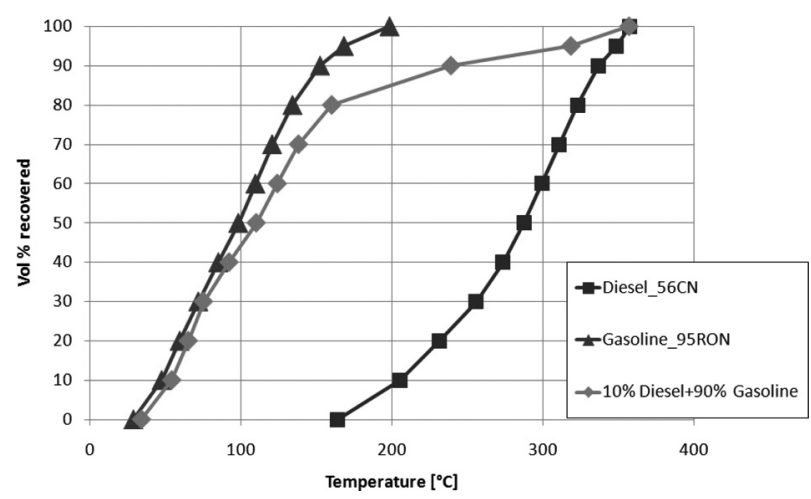

Fig. 2 Volatility characteristics of the fuels tested in the ASTM volatility test

\section{RESULTS AND DISCUSSION}

In the discussion below, all CAs (degrees) are expressed in relation to the TDC of the compression stroke which is zero; the TDC on the exhaust stroke is $360^{\circ} \mathrm{CA}$. The pressure signals are averaged over 250 cycles, and the heat release rates are calculated from the pressure signals and averaged over 250 cycles. Combustion phasing parameters such as CA50 are calculated from the integrated average heat release.

\subsection{Start-of-injection sweep}

First the low-load case at 1200 r/min will be considered. For each fuel and nozzle, the fuelling rate is fixed to obtain an IMEP for each condition at a CA50 of $10^{\circ} \mathrm{CA}$, and then the start of injection (SOI) is varied, keeping the injection pulse width constant. The SOI is in fact the CA position of the electric signal that marks the SOI rather than the actual start of fuel flow which might be measured by a needle lift device. Over the SOI range considered, the IMEP varies little for the high-cetane fuels and by up to 10 percent for the low-cetane fuels. The emission results are shown as indicated specific values to account for these changes in the IMEP.

\subsubsection{Engine speed, $1200 \mathrm{r} / \mathrm{min}$; IMEP, 2 bar; no EGR; inlet pressure, 1.1 bar; injection pressure, 250 bar}

The smoke and indicated specific nitrogen oxide $\left(\mathrm{ISNO}_{x}\right)$ emissions for GD10 fuel are relatively low and thus only the indicated specific hydrocarbon (ISHC) and indicated specific carbon monoxide (ISCO) emissions are considered in these conditions. Over the SOI range considered, the $\mathrm{HC}$ and CO emission results are shown with three different nozzles in Fig. 3 and Fig. 4 respectively and they are compared with the results using multiple injection and the level for emissions by using diesel fuel in this engine shown as a horizontal line. For the multiple injection, the start of pilot injection at $-50^{\circ} \mathrm{CA}$ is fixed and the pilot fuelling rates are varied with injection pulse widths of $300 \mu \mathrm{s}, 400 \mu \mathrm{s}$, and $500 \mu \mathrm{s}$, while the injection pulse widths of the main injections are controlled to obtain an IMEP of around 2 bar at a CA50 of $10^{\circ} \mathrm{CA}$ for each nozzle. The nozzles with higher flowrates have relatively lower $\mathrm{HC}$ and CO emissions. The normalized global air-to-fuel ratio $\lambda$ is over 4.0 in this condition and the local mixture strength, in mixture packets which burn, will be nearer the global mixture strength with a long ignition delay for GD10, the fuel used. 
Table 2 Properties of the fuels tested (MON, motor octane number; CN* of gasoline and GD10, CNs estimated using the equation $\left.\mathrm{CN}^{*}=54.6-0.42 \mathrm{RON}\right)[19]$

\begin{tabular}{|c|c|c|c|c|c|c|c|c|}
\hline & Density $\left(\mathrm{g} / \mathrm{cm}^{3}\right)$ & $\mathrm{CN}$ or $\mathrm{CN}^{*}$ & Aromatics (vol\%) & Heat of combustion $(\mathrm{MJ} / \mathrm{kg})$ & Sulphur (ppm) & Lubricity $(\mu \mathrm{m})$ & RON & MON \\
\hline Diesel (56 CN) & 0.833 & $56.2(\mathrm{CN})$ & 25.2 & 42.9 & 7 & 285 & - & - \\
\hline Gasoline (95 RON) & 0.742 & $\approx 15\left(\mathrm{CN}^{*}\right)$ & 33.45 & 43.3 & 7 & 254 & 96.2 & 84.9 \\
\hline GD10 & 0.753 & $\approx 17\left(\mathrm{CN}^{*}\right)$ & 33 & 43.3 & 7 & 255 & 91.4 & 81.5 \\
\hline
\end{tabular}

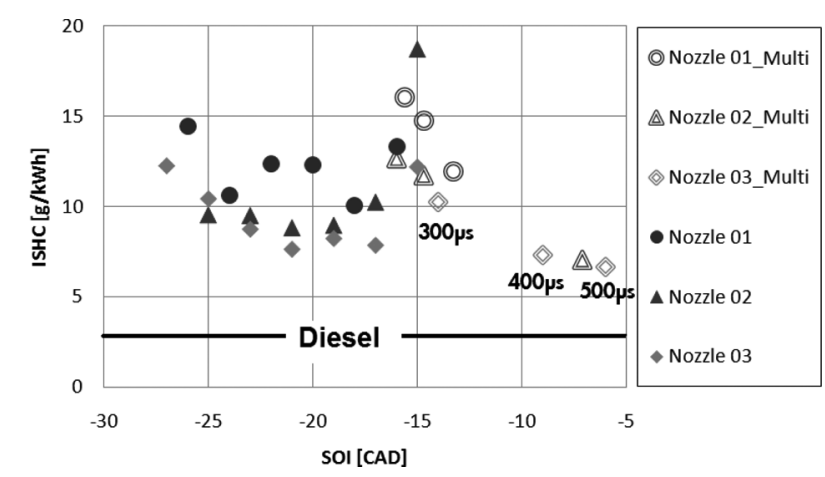

Fig. 3 ISHC versus SOI (in degrees CA (CAD)) (engine speed, $1200 \mathrm{r} / \mathrm{min}$; IMEP, 2 bar; injection pressure, 250 bar; no EGR; intake manifold temperature, $80^{\circ} \mathrm{C}$; multiple injections $(300 \mu \mathrm{s}, 400 \mu \mathrm{s}$, and $500 \mu \mathrm{s}$ pilot injection pulse widths with the start of the pilot injections at $-50^{\circ} \mathrm{CA}$ ))

Therefore the $\mathrm{HC}$ and $\mathrm{CO}$ emissions are relatively high in these conditions because of very lean mixtures. In contrast, it seems that nozzle 02 and nozzle 03 have richer mixture packets that burn compared with nozzle 01 . The multiple injections also help to reduce the $\mathrm{HC}$ and $\mathrm{CO}$ emissions with decreasing ignition delay between the start of the main injection and combustion. A high temperature $\left(80^{\circ} \mathrm{C}\right)$ in the intake manifold is required to avoid very high $\mathrm{HC}$ and $\mathrm{CO}$ emissions in these conditions.

\subsubsection{Engine speed, $1200 \mathrm{r} / \mathrm{min}$; IMEP, 4 bar; no EGR; inlet pressure, 1.1 bar; injection pressures, 250 bar and 650 bar}

The fuelling rate is fixed to obtain an IMEP of around 4 bar at a CA50 of $10^{\circ} \mathrm{CA}$ ATDC for each fuel and then the SOI is varied, keeping the injection pulse width constant. Three nozzles are investigated with two different injection pressures $(250 \mathrm{bar}$ and 650 bar) and the results are compared with diesel fuel (D1) by using nozzle 01 with an injection pressure of 650 bar. The normalized global $\lambda$ is around 2.6 and the smoke levels are low, i.e. a filter smoke number (FSN) of less than 0.08 for D1 which had the highest level compared with the others in these conditions. Figure 5 shows CA50 versus the SOI. The combustion delay (CD), which equals the CA50 minus the SOI, is a reasonably good parameter to

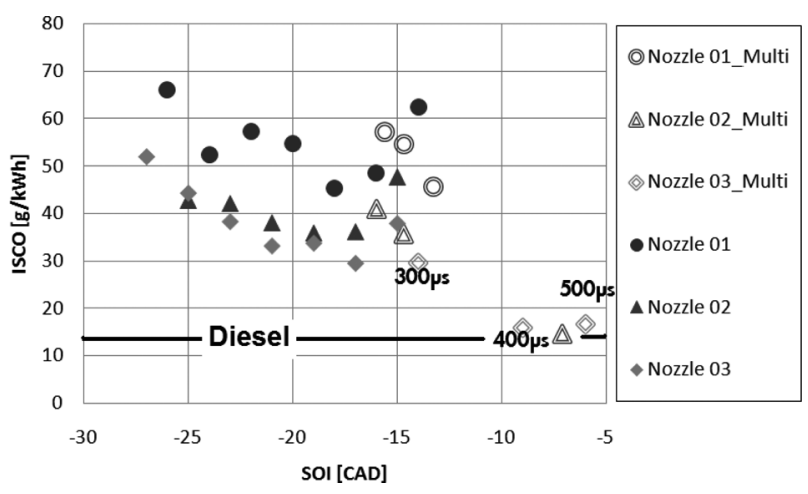

Fig. 4 ISCO versus SOI (in degrees CA (CAD)) (engine speed, $1200 \mathrm{r} / \mathrm{min}$; IMEP, 2 bar; injection pressure, 250 bar; no EGR; intake manifold temperature, $80^{\circ} \mathrm{C}$; multiple injections $(300 \mu \mathrm{s}, 400 \mu \mathrm{s}$, and $500 \mu \mathrm{s}$ pilot injection pulse widths with the start of the pilot injections at $-50^{\circ} \mathrm{CA}$ ))

help to understand fuel effects in this type of partially premixed CI combustion. The longer the CD, the more premixed are the fuel and air at the time of the main combustion. For both fuels, combustion starts after the injection is complete in these lowload conditions but the mixture strengths of the mixture packets where combustion takes place arises because of different ignition delays. When the CD is long, as for the fuel GD10, combustion occurs when the fuel and air are better mixed. The overall mixture strength, in mixture packets which burn, will be nearer the global mixture strength which is very lean $(\lambda=2.7)$. In contrast, diesel fuel ignites very soon after injection starts and the mixture packets that burn will be comparatively richer. The ignition delay for a given fuel can be reduced by reducing the injection pressure in these operating conditions. Presumably this is because of less vigorous mixing, which leads to generally richer mixture packets that ignite earlier. For the 250 bar injection pressure, nozzle 03, with the highest flowrate, shows a shorter CD. Presumably this is because the droplet sizes are higher as a result of the larger hole diameter, and mixing is less vigorous. Figure 6 shows the pressure and heat release rate for the fuels D1 and GD10, with the CA50 fixed at $10.5^{\circ} \mathrm{CA}$; the SOI was $-12^{\circ} \mathrm{CA}$ for GD10 and $+0.7^{\circ} \mathrm{CA}$ for diesel fuel at an injection pressure of 650 bar. The heat release rate for GD10 


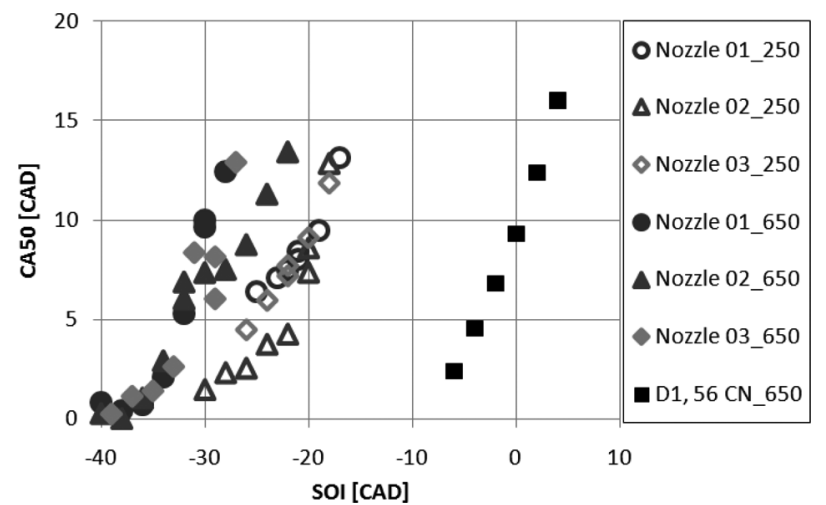

Fig. 5 CA50 versus SOI (in degrees CA (CAD)) (engine speed, $1200 \mathrm{r} / \mathrm{min}$; IMEP, 4 bar; injection pressures, $250 \mathrm{bar}$ and 650 bar; no EGR; intake manifold temperature, $60^{\circ} \mathrm{C}$ )

has a much lower peak and a wider distribution. This is because the mixture packets that burn are nearer the global mixture strength which is very lean because of the long ignition delay for GD10. The faster and higher initial heat release for higher-CN diesel fuel has a higher maximum pressure rise rate (MPRR) than fuel GD10 does in Fig. 7. In fact, at low loads in passenger car diesel engines, this is a problem because it increases noise. It is common to have a pilot injection BTDC to produce heat before the main injection in order to push the main combustion towards a mixing-controlled mode and to reduce the peak heat release rate. This reduces efficiency and increases smoke [20] which can be avoided using a gasoline-like fuel. MPRRs for the fuel GD10 are slightly increased by reducing the injection pressure. As noted previously $[\mathbf{7}, \mathbf{8}]$, when the overall mixture is very lean, more premixed combustion leads to higher HC and CO emissions. Therefore, the high-RON fuel shows much higher $\mathrm{HC}$ emissions with the same injection pressure than diesel fuel does in Fig. 8. This suggests that these higher levels of HC are caused by over-mixing of fuel and air to form mixture packets too lean to burn fully. However, HC emissions can be significantly reduced by reducing the injection pressure and, to some extent, by increasing the injection flowrate with a larger hole diameter.

\subsection{EGR sweep}

In this section the effect of EGR on each of the fuels and nozzles at $2000 \mathrm{r} / \mathrm{min}, 3000 \mathrm{r} / \mathrm{min}$, and $4000 \mathrm{r} /$ min, with an IMEP of $10 \mathrm{bar}$ is considered. The CA50 is fixed at $11^{\circ} \mathrm{CA}$ ATDC and the intake pressure, at 2.0 bar absolute, is higher than in low-load conditions. The fuelling rate is chosen to obtain a nominal IMEP without EGR, and EGR is then varied

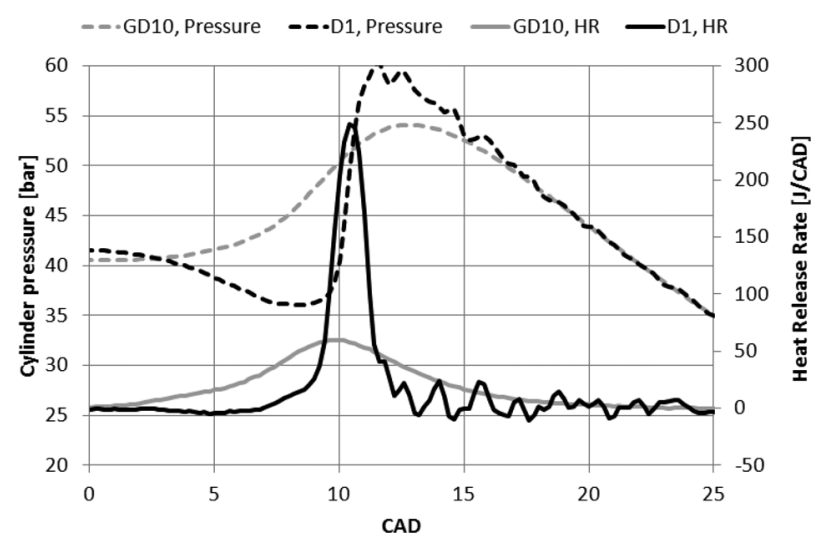

Fig. 6 Average pressure and heat release values versus $\mathrm{CA}$ (deg) (CAD) for GD10 (SOI, $-30^{\circ} \mathrm{CA}$ ) and D1 (SOI, $\left.+0.7^{\circ} \mathrm{CA}\right)\left(\mathrm{CA} 50,10.5^{\circ} \mathrm{CA}\right.$; test point 2 ; injection pressure, $650 \mathrm{bar}$; nozzle 01 )

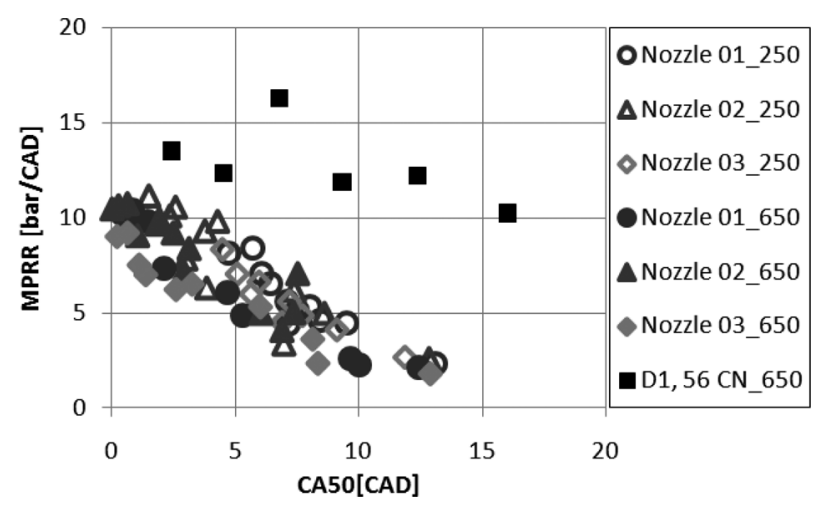

Fig. 7 MPRR (in bars per degree CA (bar/CAD)) versus CA50 (in degrees CA (CAD)) (engine speed, $1200 \mathrm{r} / \mathrm{min}$; IMEP, $4 \mathrm{bar}$; injection pressures, 250 bar and 650 bar; no EGR; intake manifold temperature, $60{ }^{\circ} \mathrm{C}$ )

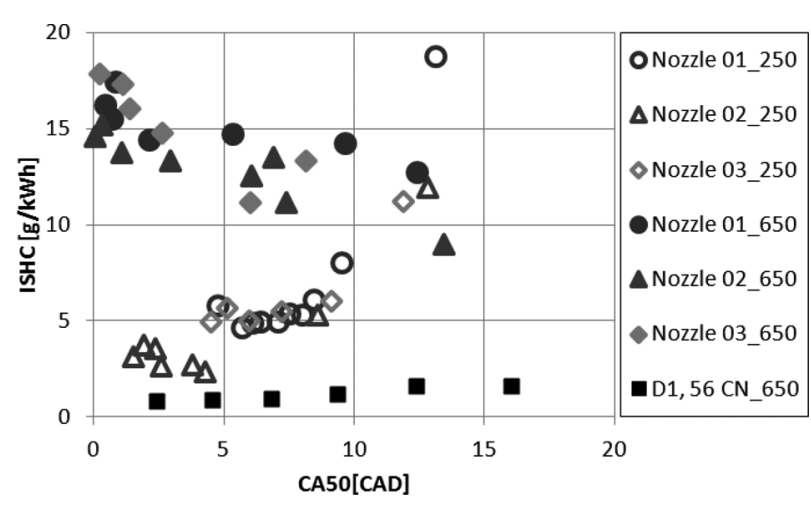

Fig. 8 ISHC versus CA50 (in degrees CA (CAD)) (engine speed, $1200 \mathrm{r} / \mathrm{min}$; IMEP, 4 bar; injection pressures, 250 bar and 650 bar; no EGR; intake manifold temperature, $60^{\circ} \mathrm{C}$ )

with the fuelling rate fixed. The EGR rate is defined as the intake $\mathrm{CO}_{2}$ concentration expressed as a percentage of the exhaust $\mathrm{CO}_{2}$ concentration. As EGR 


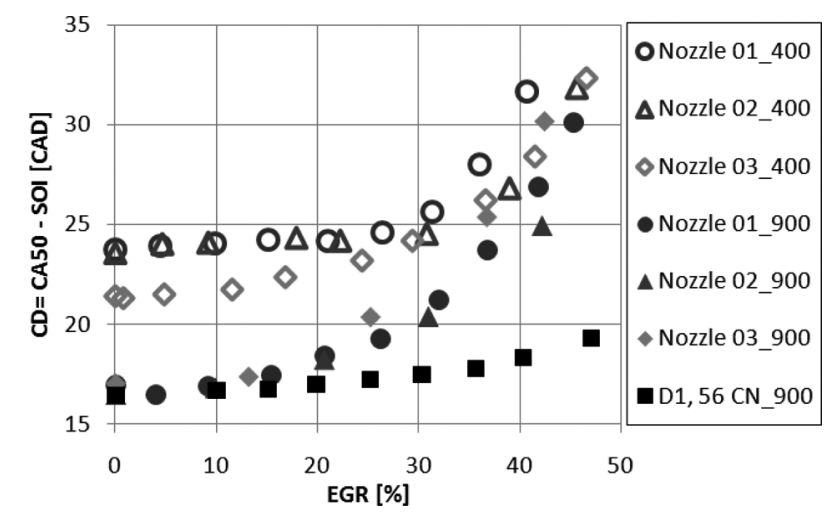

Fig. $9 \mathrm{CD}=\mathrm{CA} 50-\mathrm{SOI}$ (in degrees $\mathrm{CA}(\mathrm{CAD})$ ) versus EGR level (engine speed, $2000 \mathrm{r} / \mathrm{min}$; IMEP, 10 bar; injection pressures, 400 bar and 900 bar; CA50, $11^{\circ} \mathrm{CA}$; intake manifold temperature, $\left.60^{\circ} \mathrm{C}\right)$

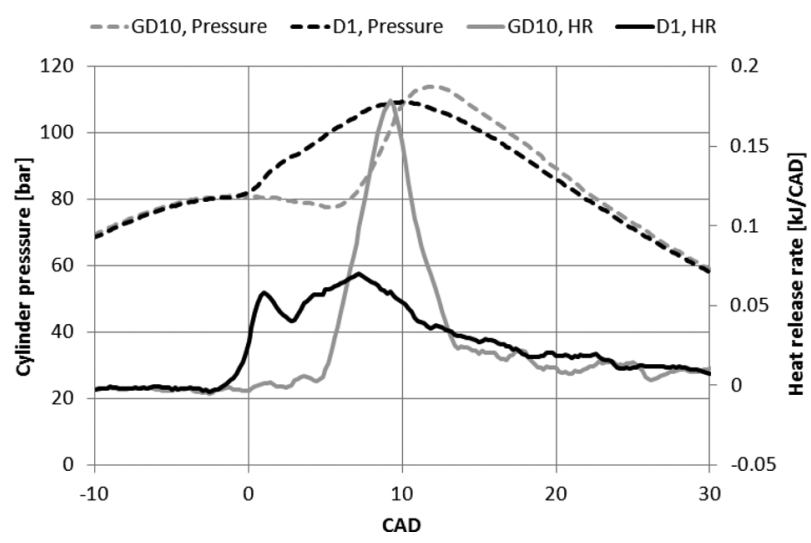

Fig. 10 Average pressure and heat release versus CA (deg) (CAD) for fuels GD10 and D1 (40\% EGR; CA50, $11^{\circ} \mathrm{CA}$; test point 4 ; injection pressure, 900 bar; nozzle 01 )

increases, both the oxygen concentration in the intake and the normalized air fuel ratio $\lambda$ decrease.

\subsubsection{Engine speed, $2000 \mathrm{r} / \mathrm{min}$; IMEP, $10 \mathrm{bar}$; CA50, $11^{\circ} \mathrm{CA}$; inlet pressure, 2.0 bar; injection pres- sures, 400 bar and 900 bar}

The GD10 fuel is investigated with two different injection pressures (400 bar and 900 bar) using the three nozzles and it is compared with diesel fuel by using nozzle 01 with an injection pressure of 900 bar. Figure 9 shows the CD plotted against the EGR level. Figures 11 and 12, discussed below, show the MPRR and the ISFC respectively plotted against the EGR level. Qualitatively, at higher engine speeds, less time is available for autoignition, and a higher intake pressure will make autoignition easier. Generally a higher injection pressure is used to compensate for the higher engine speed by not

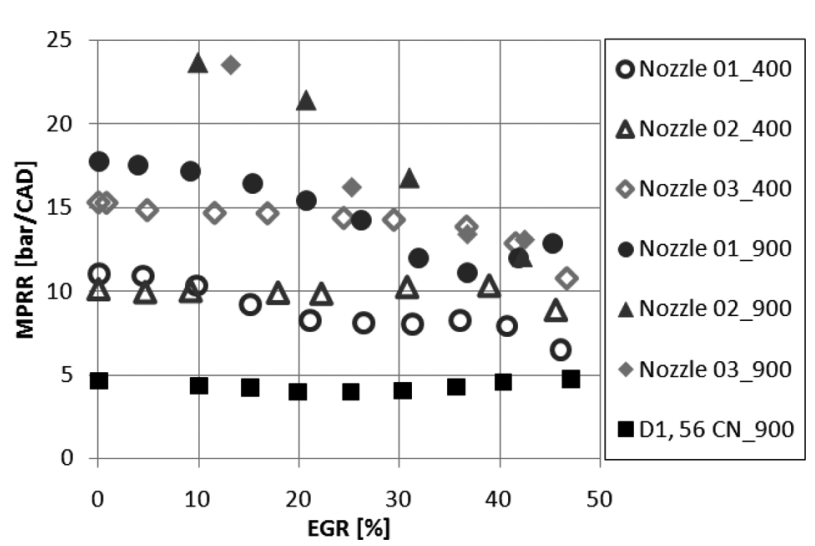

Fig. 11 MPRR (in bars per degree CA (bar/CAD)) versus EGR level (engine speed, $2000 \mathrm{r} / \mathrm{min}$; IMEP, 10 bar; injection pressures, 400 bar and 900 bar; CA50, $11^{\circ} \mathrm{CA}$; intake manifold temperature, $60^{\circ} \mathrm{C}$ )

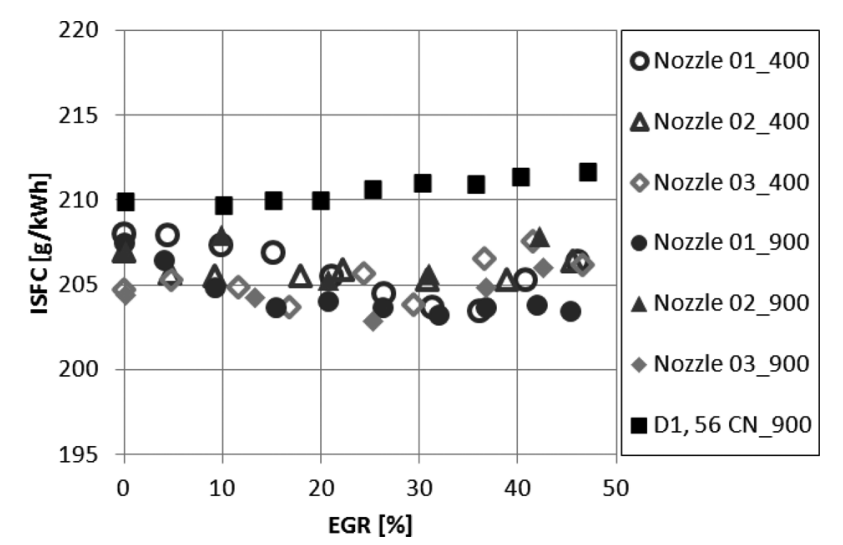

Fig. 12 ISFC versus EGR level (engine speed, 2000 r/ min; IMEP, 10 bar; injection pressures, 400 bar and $900 \mathrm{bar}$; CA50, $11^{\circ} \mathrm{CA}$; intake manifold temperature, $60^{\circ} \mathrm{C}$ )

increasing the injection duration in CA terms. The ignition delays of GD10 are longer than for diesel fuel and the difference between the two fuels increases as EGR increases in Fig. 9. At an injection pressure of $400 \mathrm{bar}$, for the GD10 fuel, the CD is shorter for nozzle 03 with the highest hole diameter. Figure 10 shows the pressures and heat release rates for diesel fuel and GD10 fuel in these conditions with 40 per cent EGR, nozzle 01 , and an injection pressure of 900 bar. In the case of diesel fuel, most of the fuel is injected after the start of combustion and burns in a diffusion flame; thus the heat release for diesel fuel has a very short premixed combustion phase and a long mixing-controlled combustion phase. This causes large amounts of soot to be formed, which cannot be oxidized sufficiently because of the high EGR level. On the other hand, all the GD10 fuel is injected before the start of combustion. However, the MPRRs for GD10 are higher 


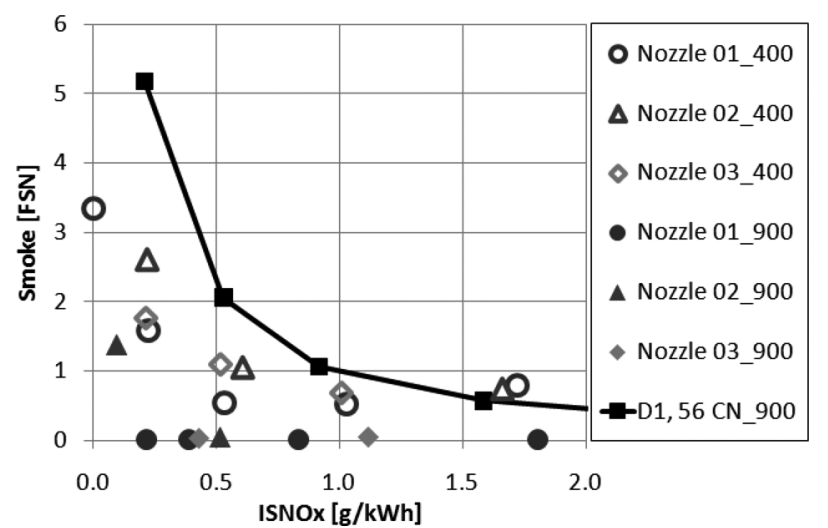

Fig. 13 Smoke versus $\mathrm{ISNO}_{x}$ (engine speed, 2000 r/ min; IMEP, 10 bar; injection pressures, 400 bar and $900 \mathrm{bar}$; $\mathrm{CA} 50,11^{\circ} \mathrm{CA}$; intake manifold temperature, $60^{\circ} \mathrm{C}$ )

in Fig. 11 because combustion is taking place in a relatively rich premixed phase. The MPRRs are reduced by high EGR and low injection pressure but they are still higher than the level for diesel fuel. Of the three nozzles, nozzle 02 and nozzle 03 have higher MPRRs than the standard nozzle does at low EGR but this difference is reduced as EGR increases. Figure 12 shows that the fuel consumption for GD10 is slightly lower than for diesel fuel, presumably because the heat release is not spread out too far away from TDC. With the slightly longer delay times, as for GD10, combustion will start with the mixture packets still rich but nearer the stoichiometric mixture strength, on average, than for the diesel fuel. Hence the MPRRs for GD10 are higher than for diesel fuel in these conditione. When the combustion phasing is fixed, as in the present case, as EGR is increased for a given fuel, the combustion temperature and consequently the heat loss decrease, and also the fuel consumption decreases $[7,15]$ However, if smoke is formed in the first place as with diesel fuel, the smoke emissions are increased as EGR is increased by decreasing the oxygen available and the combustion temperature, even if ignition delays are increased. In these conditions, diesel fuel has an overlap between the injection and heat release, and the combustion is mixing controlled to a significant extent. In Fig. 13, the FSN is plotted against $\mathrm{ISNO}_{x}$ and it can be seen that low$\mathrm{NO}_{x}$ low-smoke combustion is possible with GD10 (even with an injection pressure of 400 bar) but not with the diesel fuel (even with an injection pressure of $900 \mathrm{bar}$ ). The emissions depend on the time history of the mixture strength and the burned gas temperature in all the mixture, which in turn is determined by the mixing of fuel and air. The processes involved are complex and depend on the

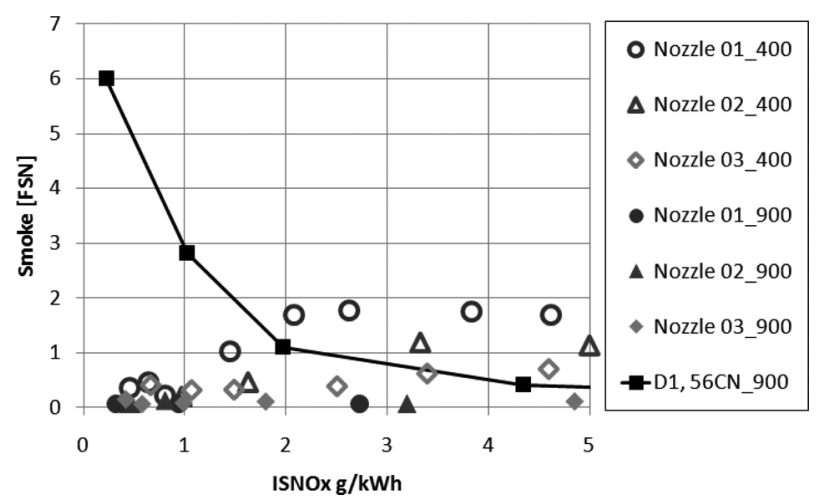

Fig. 14 Smoke versus EGR level (engine speed, $3000 \mathrm{r}$ / min; IMEP, 10 bar; injection pressures, 400 bar and $900 \mathrm{bar}$; CA50, $11^{\circ} \mathrm{CA}$; intake manifold temperature, $60^{\circ} \mathrm{C}$ )

ignition delay, the injection pressure, the fuel volatility, the surrounding temperature, and the flow field among other factors.

\subsubsection{Engine speeds,3000 r/min and $4000 \mathrm{r} / \mathrm{min}$; IMEP, 10 bar; $C A 50,11^{\circ} \mathrm{CA}$; inlet pressure, 2.0 bar; injection pressures, 400 bar and $900 \mathrm{bar}$}

These conditions are again identical with those considered in the previous section except that the engine speeds are faster. As the engine speed increases, the time available for combustion decreases. Hence, if the ignition delay is too long, ignition cannot happen before the pressure and temperature in the cylinder are reduced rapidly during the expansion stroke and combustion fails. In such cases, combustion can be ensured by increasing the intake pressure slightly [5]. 91 RON gasoline could not be run at high levels of EGR because the combustion becomes unstable [7]. The results of the CD, MPRR, and ISFC show similar trends to the results in section 3.2.3, and thus only the smoke and $\mathrm{ISNO}_{x}$ emissions are discussed in these two conditions. First, Fig. 14 shows the smoke emissions against the $\mathrm{ISNO}_{x}$ emissions at an engine speed of $3000 \mathrm{r} / \mathrm{min}$. The maximum EGR for GD10 is around 45 percent in these conditions because above this value the combustion becomes unstable. Increasing EGR leads to lower $\mathrm{ISNO}_{x}$ and higher smoke emissions for diesel fuel. The GD10 fuel with high RON can be run with high EGR to reduce the $\mathrm{NO}_{x}$ emissions without increasing the smoke emissions because smoke formation is avoided in the first place owing to the long ignition delay. The $\mathrm{ISNO}_{x}$ emissions are below $0.5 \mathrm{~g} / \mathrm{kW}$ h with very low smoke emissions even at a low injection pressure. It seems that GD10 at low EGR levels has a short overlap 
between the injection and the heat release. Consequently the smoke emissions are increased when the injection pressure is reduced. However, the smoke levels for GD10 even with an injection pressure of 400 bar are lower than $0.5 \mathrm{FSN}$ even at high EGR (less than 30 per cent). Figure 15 shows a trade-off between the smoke emissions and the $\mathrm{ISNO}_{x}$ emissions at an engine speed of $4000 \mathrm{r} / \mathrm{min}$. The levels of EGR are limited again in these conditions because of unstable combustion for the highRON fuel. The engine can be run with up to 35 per cent EGR for the GD10 fuel and the $\mathrm{ISNO}_{x}$ emissions are around $0.7 \mathrm{~g} / \mathrm{kWh}$ in these conditions. The smoke emissions for the third nozzle even with an injection pressure of $400 \mathrm{bar}$ are lower than 0.5 FSN at most levels of EGR and they are similar to the levels with an injection pressure of 900 bar. Increasing the injector hole size would enable the injection event to be completed more quickly for a fixed injection pressure and fixed amount of fuel injected. When the fuel is very resistant to autoignition and the global mixture strength is lean or dilute, it is important not to over-mix the fuel, and reducing the injection pressure improves the combustion process significantly $[\mathbf{5}, \mathbf{2 1}]$. Thus, with high-RON fuels, larger injector holes allied with lower injection pressures and multiple injections might improve the combustion process, as the results in this paper suggest. Such an approach would increase the smoke emissions with fuels in the diesel autoignition range $(\mathrm{CN}>40)$ because of the very short ignition delays. With high-RON fuels, good mixing does not depend exclusively on the injection process but is affected by the fact that there is much more time available for mixing before autoignition.

\subsection{Trade-offs of emissions}

In this section the low emissions available at each test point are considered. The test points are described in Table 3. Three test points in low-load

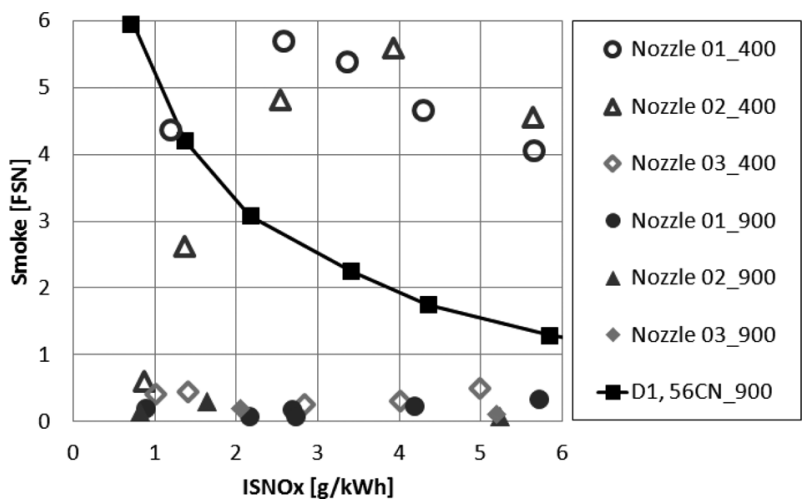

Fig. 15 Smoke versus $\mathrm{ISNO}_{\mathrm{x}}$ (engine speed, 4000 r/ min; IMEP, 10 bar; injection pressures, 400 bar and $900 \mathrm{bar}$; CA50, $11^{\circ} \mathrm{CA}$; intake manifold temperature, $60^{\circ} \mathrm{C}$ )

conditions and another three test points in higherload conditions are selected for this study. The test points are defined by their IMEPs and engine speeds, both of which are maintained constant for all the tests under a given test point. The SOI and rail pressure are varied within the shown limits (up to 900 bar for diesel fuel and up to 400 bar for GD10 fuel). The injection duration is varied to maintain the IMEP as specified in Table 3, while specified levels of $\mathrm{NO}_{x}$ are achieved by varying EGR. Figure 16 shows the ISHC level against the MPRR at six different test points and the sizes of the symbols are increased from test point (smallest) to test point 6 (largest). The results are selected at the lowest level possible at each test point with SOI sweeps and EGR sweeps, and the targets are also shown within the black box. Diesel fuel can be run in all conditions to obtain ISHC and MPRR values below the targets, but GD10 in low-load conditions has high HC emissions and MPRRs for nozzle 3 are also high in highload conditions. This is an inevitable result of lean premixed combustion. If the conditions are such that the $\mathrm{NO}_{x}$ and smoke emissions are controlled, the combustion temperatures and the mixture

Table 3 Test points

\begin{tabular}{|c|c|c|c|c|c|c|}
\hline & \multicolumn{6}{|c|}{ Value for the following } \\
\hline & Test point 1 & Test point 2 & Test point 3 & Test point 4 & Test point 5 & Test point 6 \\
\hline Engine speed (r/min) & 1200 & 1200 & 2000 & 2000 & 3000 & 4000 \\
\hline \multicolumn{7}{|l|}{ Rail pressure (bar) } \\
\hline Diesel & - & 650 & 900 & 900 & 900 & 900 \\
\hline GD10 & 250 & 250 & 400 & 400 & 400 & 400 \\
\hline IMEP (bar) & 2 & 4 & 4 & 10 & 10 & 10 \\
\hline Boost pressure (bar) & 1.1 & 1.1 & 2.0 & 2.0 & 2.0 & 2.0 \\
\hline Exhaust pressure (bar) & 1.1 & 1.1 & 2.2 & 2.2 & 2.2 & 2.2 \\
\hline Boost temperature $\left({ }^{\circ} \mathrm{C}\right)$ & 80 & 60 & 60 & 60 & 60 & 60 \\
\hline Oil and coolant temperatures $\left({ }^{\circ} \mathrm{C}\right)$ & 90 & 90 & 90 & 90 & 90 & 90 \\
\hline$\lambda$ (no EGR) & 4.5 & 2.7 & 4.8 & 2.3 & 2.3 & 2.3 \\
\hline
\end{tabular}




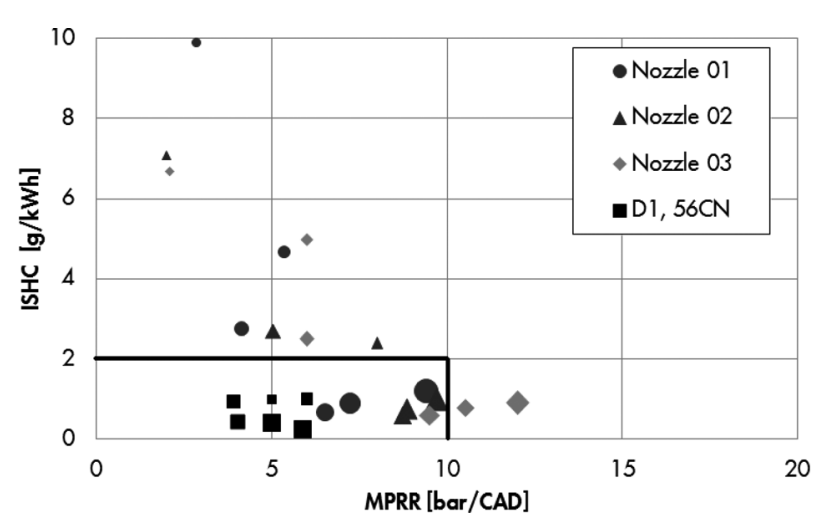

Fig. 16 ISHC versus MPRR (in bars per degree CA (bar/CAD)) at six different test points; the sizes of the symbols increased from test point 1 (smallest) to test point 6 (largest)

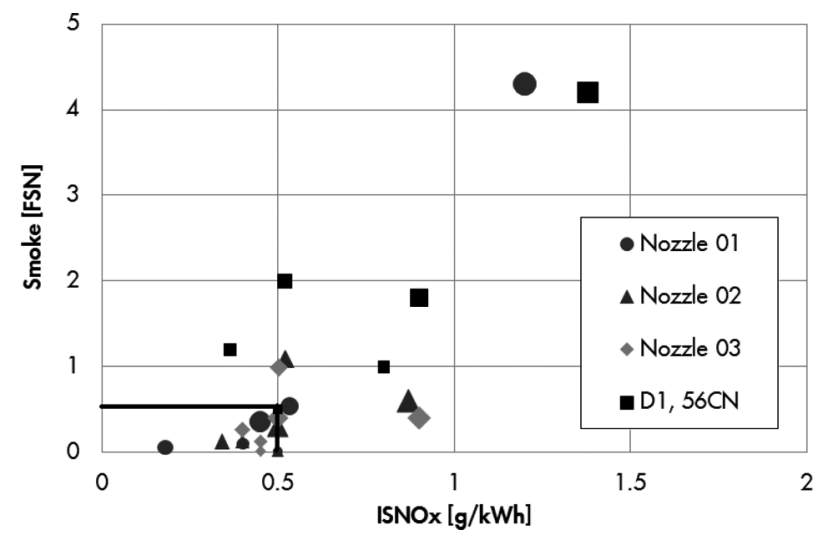

Fig. 17 Smoke versus ISNO $_{\mathrm{x}}$ at six different test points; the sizes of the symbols increased from test point 1 (smallest) to test point 6 (largest)

strengths will be such that $\mathrm{HC}$ and $\mathrm{CO}$ do not go to full oxidation even if there is oxygen available. Figure 17 shows the smoke emisions versus the $\mathrm{ISNO}_{x}$ emissions, and the black box is again the target for Euro norm 6 for emission. Diesel fuel can be run in most conditions with sufficient EGR to obtain $\mathrm{ISNO}_{x}$ levels below $0.5 \mathrm{~g} / \mathrm{kWh}$ but the smoke emissions are increased dramatically at high EGR levels. The results for diesel fuel are the nearest value at each test point to the target in trade-off between smoke and $\mathrm{NO}_{x}$ emissions. Even if the engine is operated with a high injection pressure, diesel fuel has high smoke and $\mathrm{ISNO}_{x}$ emissions in most conditions. The trade-offs for GD10 fuel are very close to the target in all conditions, and GD10 fuel has lower smoke and $\mathrm{NO}_{x}$ emissions than diesel fuel does. The high-RON fuel can be run in most conditions with sufficient EGR to obtain $\mathrm{ISNO}_{x}$ levels below $0.5 \mathrm{~g}$ / $\mathrm{kW} h$ with very low smoke emissions of $0.5 \mathrm{FSN}$ even with a low injection pressure. However, the emissions are outside the black box at $4000 \mathrm{r} / \mathrm{min}$ because of more difficult ignitions at high engine speeds. This could be solved by increasing the higher intake pressure. However, $\mathrm{NO}_{x}$ and smoke emissions can be controlled at much higher loads at a given speed with gasoline-like fuels compared with diesel fuels. This would enable downsizing and down-speeding in light-duty engines with associated benefits in fuel economy. Using multipleinjection strategies, low-emission high-efficiency operation has been achieved at full load in heavyduty engines using gasoline and ethanol [13, 14].

\section{SUMMARY AND CONCLUSIONS}

A blended fuel GD10 (90 vol\% of 95 RON gasoline and $10 \mathrm{vol} \%$ of $56 \mathrm{CN}$ diesel) is tested in a small (0.537 l) single-cylinder compression ignition engine using three different nozzles, and is compared with diesel fuel in different operating conditions.

1. At low loads, with a very lean global mixture strength, GD10 gives significantly lower $\mathrm{NO}_{x}$ emissions and MPRR but higher $\mathrm{HC}$ and $\mathrm{CO}$ emissions because of longer ignition delays compared with the results for diesel fuel. A low injection pressure and nozzles with higher flowrates are used to avoid over-mixing to lower the $\mathrm{HC}$ and $\mathrm{CO}$ emissions in low-load conditions.

2. GD10 fuel can be run with sufficient EGR in higher-load conditions to obtain a low $\mathrm{ISNO}_{x}$ level with low smoke levels because of the long ignition delay. In the same conditions, diesel fuel gives very high smoke emissions at high EGR levels.

3. As the engine speed increases, fuels with greater autoignition resistance become less tolerant to EGR, as expected. However, low smoke and $\mathrm{NO}_{x}$ emissions are possible by using a larger-orifice nozzle at high EGR levels even with a low injection pressure.

Thus, these tests suggest that larger injector hole diameters and lower injection pressures are better for gasoline fuels in PPCI because they can help to alleviate some of the problems associated with premixed combustion such as high $\mathrm{HC}$ and $\mathrm{CO}$ emissions. The injector variations that have been considered in this work are not large. A narrowangle direct-injection system will be considered for further study to improve combustion and emissions for high-RON fuels by using early-timing injection strategies. Clearly, much development work is needed to optimize injectors and injection strategies to make the best use of the long ignition delays of gasoline-like fuels to obtain low $\mathrm{NO}_{x}$ and low smoke emissions with high efficiency from CI engines. Low- $\mathrm{NO}_{x}$ low-smoke high-efficiency CI combustion 
is likely to benefit from low-CN diesel or low-RON gasoline by today's standards and lower injection pressures compared with current diesel engines. Moreover, the focus for after-treatment shifts from $\mathrm{NO}_{x}$ control to HC and CO control. There is much incentive and also scope to develop such engine combustion systems.

\section{FUNDING}

This work was supported by an EU contract [grant no. FP7;251492], Marie Curie Low Carbon Future Fuels, under the Marie Curie Programme, which made the collaboration with RWTH Aachen University possible.

\section{ACKNOWLEDGEMENTS}

Colleagues in the Shell Technology Centre Thornton, most notably H. Jones and R. Head, made the engine experiments possible.

\section{(C) Authors 2011}

\section{REFERENCES}

1 Dec, J. E. Advanced compression ignition engines understanding the in-cylinder processes. Proc. Combust. Inst., 2009, 32, 2727-2742.

2 Heywood, J. B. Internal combustion engine fundamentals, 1988, pp. 491-516 (McGraw-Hill, New York).

3 Kalghatgi, G. T., Risberg, P., and Ångström, H. Advantages of fuels with high resistance to autoignition in late-injection, low-temperature, compression ignition combustion. SAE paper 2006-013385, 2006.

4 Kalghatgi, G. T., Risberg, P., and Ångström, H. Partially pre-mixed auto-ignition of gasoline to attain low smoke and low $\mathrm{NO}_{x}$ at high load in a compression ignition engine and compared with a diesel fuel. SAE paper 2007-01-0006, 2007.

5 Kalghatgi, G., Hildingsson, L., and Johansson, B. Low $\mathrm{NO}_{\mathrm{x}}$ and low smoke operation of a diesel engine using gasoline-like fuels. In Proceedings of the ASME Internal Combustion Engine Division 2009 Spring Technical Conference (ICES 2009), Milwaukee, Wisconsin, USA, 3-6 May 2009, ASME paper ICES 2009-76034 (ASME, New York).

6 Kalghatgi, G., Hildingsson, L., and Johansson, B. Low $\mathrm{NO}_{x}$ and low smoke operation of a diesel engine using a gasoline fuel. In Proceedings of the IMechE Conference on Internal combustion engine: performance, fuel economy and emissions, London, UK, 8-9 December 2009, paper C684027 (Woodhead Publishing, Cambridge).

7 Hildingsson, L., Kalghatgi, G., Harrison, A. J., and Johansson, B. Some effects of fuel auto-ignition quality and volatility in premixed compression ignition engines. SAE paper 2010-01-0607, 2010.

8 Kalghatgi, G., Hildingsson, L., Harrison, A. J., and Johansson, B. Low $\mathrm{NO}_{x}$ and low smoke operation of a diesel engine using premixed enough compression ignition: effects of fuel auto-ignition quality and volatility and aromatic content. In Proceedings of the THEISEL 2010 Conference on Thermo and dynamic processes in diesel engines, Valencia, Spain, 14-17 September 2010, pp. 409420 (Universitat Politècnica de València, Valencia, Spain).

9 Hildingsson, L., Kalghatgi, G., Harrison, A. J., and Johansson, B. Auto-ignition quality of gasoline fuels in partially premixed combustion in diesel engines. Proc. Combust. Inst., 2011, 33, 3015-3021.

10 Li, T., Okabe, Y., Izumi, H., and Ogawa, H. Dependence of ultra-high EGR low temperature combustion on fuel properties. SAE paper 2006-01-3387, 2006.

11 Risberg, P., Kalghatgi, G., and Ångström, H. Autoignition quality of diesel-like fuels in HCCI engines. SAE paper 2005-01-2127, 2005.

12 Schleyer, G. H., Duffy, K. P., Liechty, M. P., Hardy, W. L., and Bessonette, P. W. Effects of fuel property changes on heavy duty HCCI combustion. SAE paper 2007-01-0191, 2007.

13 Manente, V., Johansson, B., and Tunestål, P. Partially premixed combustion at high load using gasoline and ethanol, a comparison with diesel. SAE paper 2009-01-0944, 2009.

14 Manente, V., Johansson, B., Tunestål, P., and Canella, W. Effects of different types of gasoline fuels on heavy duty partially premixed combustion. SAE paper 2009-01-2668, 2009.

15 Hanson, R., Splitter, D., and Reitz, R. Operating a heavy-duty direct-injection compression-ignition engine with gasoline for low emissions. SAE paper 2009-01-1442, 2009.

16 Weall, A. J. and Collings, N. Investigation into partially premixed compression ignition in a light duty multi cylinder engine: a study of low load and low speed operation. SAE paper 2007-01-4058, 2007.

17 Weall, A. J. and Collings, N. Gasoline fuelled partially premixed compression ignition in a light duty multi cylinder engine: a study of low load and low speed operation. SAE paper 2009-01-1791, 2009.

18 Sellnau, M., Sinnamon, J., Hoyer, K., and Husted, H. Gasoline direct injection compression ignition (GDCI) - diesel-like efficiency with low $\mathrm{CO}_{2}$ emissions. SAE paper 2011-01-1386, 2011.

19 Kalghatgi, G. T. Auto-ignition quality of practical fuels and implications for fuel requirements of future SI and HCCI engines. SAE paper 2005-01-0239, 2005.

20 Kalghatgi, G. T., Gurubaran, K., Davenport, A., Harrison, A. J., Taylor, A. K. M. F., and Hardalupas, Y. Some advantages and challenges of running a Euro IV V6 diesel engine on a gasoline fuel. In Proceedings of the Eighth International Symposium: Towards clean diesel engines (TCDE 2011), Chester, Cheshire, UK, 8-9 June 2011 (Shell Global Solutions, Chester, UK).

21 Hildingsson, L., Kalghatgi, G, Tait, N., Johansson, B., and Harrison, A. Fuel octane effects in the partially premixed combustion regime in compression ignition engines. SAE paper 2009-012648, 2009. 